\title{
A Criação de uma Cultura de Grupo na Brincadeira: Um estudo com crianças entre 2 e 4 anos
}

\author{
Josiane da Silva Delvan \\ Maiara Pereira Cunha \\ Universidade do Vale do Itajaí
}

\begin{abstract}
RESUMO
O presente estudo procurou analisar como um grupo de crianças de 2 a 4 anos de idade se estrutura durante a atividade de brincadeira, e discutir a cultura de grupo por elas elaborada nesta atividade. Com base nos aportes teóricos da psicologia histórico-cultural e da sociologia da infância, este trabalho teve como participantes um grupo composto por seis crianças com idade entre dois e quatro anos (três meninos e três meninas, um de cada idade), pertencentes a uma instituição pública de Educação Infantil, sendo que o instrumento utilizado para coleta de dados foi a observação vídeogravada. O material coletado foi organizado e seguiu os procedimentos de análise qualitativa de episódios definidos na literatura especializada. Os resultados indicam que as culturas infantis são elaboradas por meio dos embates criados nas negociações que as crianças estabelecem no processo reprodutivo e criativo de dar sentido à sociedade, aos outros e a si, numa postura ativa de dar significado às suas ações com base na sua realidade.
\end{abstract}

Palavras-chave: brincadeira; crianças; construção de significados; cultura de grupo; desenvolvimento humano.

\section{ABSTRACT \\ The Rising of a Group Culture in Play: A study of children between the ages 2 and 4}

This study was designed to analyse how a group of children from the ages of 2 to 4 structure themselves in the activity of playing and discuss the group culture created by them in this activity. The research was based on the theoretical constructs of historic-cultural psychology and infancy sociology. A group composed of six children between 2 and 4 (three boys and three girls, one of each age) belonging to a public institution nursery school were monitored with the aid of video recording. Qualitative analysis of the video episodes were defined in accordance with the specialized literature. The results indicate that the childhood cultures were created by ways of conflicts arising in the negotiations that these children establish in the reproductive and creative process of giving sense to society, to others and themselves, with an active position of giving meaning to their actions based in their reality.

Keywords: games, children, meaning-building, group culture, human development.

A investigação da cultura de crianças é um campo bastante recente e implica na necessidade de metodologias investigativas não apenas sobre elas, mas com elas, para que realmente seja possível captar os modos como se organizam, como interagem com as pessoas, com as instituições, como reagem aos adultos e desenvolvem estratégias de participação no mundo que as cerca. A perspectiva teórico-metodológica proposta por Rossetti-Ferreira, Amorim \& Silva (2004) define que o desenvolvimento humano é compreendido como um processo complexo e imerso em uma malha de elementos de natureza semiótica em contínua transformação. Nela, a subjetividade de várias pessoas se constitui conforme elas interagem em diversas situações construindo e/ou re-elaborando significações que se ligam formando uma rede. As atividades dos sujeitos nessas situações envolvem papéis ou posições que são assumidos, confrontados, negados ou negociados, estruturando o enredo das ações construídas, o que revoluciona seu desenvolvimento e os leva a alterar significativamente sua rede de significações e eventuais significados partilhados com os demais. 
Assim, o desenvolvimento se caracteriza como um processo de mudanças que ocorre ao longo da vida, provocado pelos embates vividos pelas pessoas em diferentes situações, processo que inclui o confronto de múltiplas vozes na concepção de Bakthin (1992), oriundas de contextos e períodos históricos específicos que atuam sobre as pessoas e lhes possibilitam experimentar continuidade e mudança, a persistência do velho e a criação do novo. Tal perspectiva nos alerta, contudo, para a necessidade de não nos restringir ao fator interpessoal e olhar os condicionantes macroestruturais históricos (que, na perspectiva, constituem a matriz sócio-histórica), que medeia a construção de significados marcados histórica e ideologicamente.

Alguns estudos vêm avançando na compreensão da intersubjetividade enquanto constitutiva do ser humano e do seu processo de desenvolvimento (Anjos, Amorim, Franchi, Vasconcelos \& Rossetti-Ferreira, 2004; Franchi, Vasconcelos \& Ferreira, 2002; Oliveira, 1988). Essas investigações têm buscado analisar o contexto da Educação Infantil como um ambiente onde as interações se concretizam promovendo o processo de desenvolvimento de crianças e adultos em determinadas direções. Como lugar de confronto e de partilha de significados, as situações que se estabelecem em creches e pré-escolas têm exigido dos estudiosos um olhar apurado sobre a participação das crianças na construção das culturas infantis que, por sua vez, possibilitam novas construções conjuntas de ações e sentidos no grupo de brincadeira.

A compreensão dos processos de produção e negociação de significados e sentidos requer o exame da noção de interação social. Para tanto vamos recorrer à Vygotsky (2007), para quem o organismo e o meio biológico e cultural influenciam-se reciprocamente durante toda a vida promovendo o desenvolvimento humano que se constitui nas relações entre os sujeitos humanos à medida que as bases biológicas da espécie são moldadas pela cultura da qual eles participam ativamente. A interação é entendida como o confronto de ações constitutivas dos papéis que as crianças assumem em uma situação. É neste confronto de ações e significados que as crianças constroem um modo próprio de se organizarem sendo a contradição a condição deste processo (Oliveira, 1988; 1995).

O desenvolvimento humano nessa perspectiva se constitui a partir da atividade do sujeito, possibilitada ou limitada pelas interações sociais que se realizam em ambientes organizados cultural e historicamente e que se fazem presentes desde os primeiros momentos de nossa existência. Segundo Newman e Holzman (2002), fundamentados na concepção vygotskiana, o que revoluciona o desenvolvimento é a atividade de criar outros significados na ação mudando a situação em que ela ocorre, tais como podemos observar na brincadeira de crianças. As crianças na atividade de brincadeira de faz-de-conta interpretam a realidade segundo uma lógica peculiar que caracteriza a sua cultura de grupo (Delgado \& Müller, 2005b). Tal interpretação não é simplesmente uma adaptação ou interiorização do mundo adulto, mas uma postura ativa de dar significado ao mundo. Isto confere legitimidade ao grupo infantil pelo fato de participar de um conjunto de práticas, representações e relações próprias da infância em suas diferentes etapas, o que lhes possibilita o desenvolvimento de certas capacidades para o entendimento do mundo.

A cultura de grupo tem sido estudada pela Sociologia da Infância, que tem ressaltado o lugar da criança na ciência e na sociedade como membro ativo na reprodução e construção da cultura, e como os adultos podem compreendê-la enquanto sujeito no seu processo de socialização (Corsaro, 2005; Delgado \& Müller, 2005a, 2005b; Ferreira, 1999; 2002a, 2002b; Javeau, 2005; Mollo-Bouvier, 2005; Montandon, 2001; Sarmento, 2005, Sirota, 2001). As crianças vivem inseridas em uma cultura adulta e têm relativa autonomia para interpretá-la. Por isso, Corsaro (2005) usa o termo reprodução interpretativa para definir a capacidade das crianças para produzirem sentidos e construírem uma cultura nas suas interações, mas especificamente, no grupo de brincadeira. Para este autor, a cultura de grupo é um conjunto de atividades, rotinas, artefatos, valores e preocupações que adquirem significados pelas crianças e são por elas também resignificadas na interação com seus pares. Também para Sarmento (2005), pode-se considerar os papéis e práticas sociais de crianças de uma determinada faixa etária vivenciadas no grupo. Para Javeau (2005), as culturas infantis são elaboradas no grupo por meio da partilha de sentidos e dos embates inerentes a qualquer negociação existente entre os envolvidos num processo reprodutivo e criativo de dar sentido à sociedade, aos outros e a si num território lúdico ocupado predominantemente pelas crianças. Elas se apropriam, reproduzem e inovam os sentidos atribuídos ao mundo individual e coletivamente, transformando a cultura do grupo de pares que, para Montandon (2001) pode incluir posturas de negação, ou de oposição e até de argumentação, nas conversações presentes nas complexas interações que as crianças estabelecem. Tem-se 
aqui uma questão complexa e polêmica: as crianças criam? O que criam? O que significa essa criação para a sociedade de modo geral e para a própria criança?

Estudos em psicologia do desenvolvimento sobre os grupos infantis e suas produções apontam que durante a brincadeira, as crianças transformam os objetos por meio da imaginação, que lhes possibilita fundir passado, presente e futuro, e também transitar entre o real e o imaginário, deparando-se com as contradições e limitações entre estes dois mundos. Dornelles (2001) afirma que ao brincar, a criança em cada fase da sua vida tem a possibilidade de dar um significado diferente, como também aos poucos, começa a buscar certa "coerência e lógica nas suas ações nas brincadeiras" (p. 105). Desta maneira pode experienciar e confrontar a tarefa de se relacionar através do brinquedo com o outro, construindo uma maneira singular de interagir naquela situação. Daí a importância de estudos que considerem a capacidade das crianças na situação de brincadeira em grupo de interpretar o mundo e construir uma microcultura a partir da macrocultura (Carvalho \& Pedrosa, 2002).

Essa capacidade da criança de renovar a cultura e provocar mudanças significativas no seu desenvolvimento a partir da brincadeira é reconhecida por Vygotsky. Segundo este, na brincadeira a atividade humana é revolucionária, ou seja, liga-se à capacidade do ser humano de fazer história, de criar e alterar as circunstâncias de sua existência. Isso inclui tanto as próprias formas do sujeito agir, sentir, pensar, como as condições de produção destas formas em uma sociedade concreta. Como a atividade humana se realiza na possibilidade de significar sua própria ação, a atividade revolucionária já está presente na primeira infância, ponto que explicaria, por exemplo, a aprendizagem da língua, entendida como um processo de significação.

\section{MÉTODO}

Para discutir como se dá a construção de uma cultura no grupo de crianças de 2 a 4 anos de idade em creche, optou-se por analisar um episódio extraído de material de vídeo-gravação de 13 sessões com aproximadamente 30 minutos cada uma em uma instituição pública de Educação Infantil de um município do litoral catarinense, gravadas entre julho a dezembro de 2003 e que fazem parte de um estudo maior (Delvan, 2007).

Os procedimentos de coleta de dados para o referido estudo foram realizados em fases distintas e complementares: na primeira fase foi realizada a observação das crianças com idade mista em suas respectivas turmas em atividade de brincadeira espontânea para a identificação dos participantes que comporiam o grupo para as sessões de observação. Juntamente com estas observações, foram realizados contatos com as professoras para que elas apontassem quais as crianças de cada turma que mais interagiam durante as situações de brincadeira. A partir destas informações, de cada turma foram escolhidas 5 ou 6 crianças dentre as que aceitaram participar das filmagens. Em seguida, foi solicitado aos pais ou responsáveis pelas crianças a autorização para participação delas nas filmagens. $\mathrm{Na}$ segunda fase foram realizadas as sessões de vídeogravação com seis crianças com 2 a 4 anos de idade em atividade de brincadeira livre numa das salas de aula da instituição disponibilizada para tal procedimento. O grupo foi organizado desta forma buscando maximizar o contato de crianças com diferentes idades. Assim, havia uma menina e um menino de cada idade no grupo para a observação.

Dada a necessidade de se apreender o processo interacional na investigação, a transcrição das observações vídeo-gravadas buscou detalhar as falas, os movimentos, a expressão gestual e facial, e para quem ela era dirigida, assim como com quem e de que forma os objetos eram manipulados. Para cada uma das treze sessões filmadas, foram transcritos de forma molar (mais geral) os comportamentos observados nos 10 primeiros minutos. Após a transcrição das sessões filmadas, o material foi assistido várias vezes para aperfeiçoar a descrição das ações, das falas e identificar a formação das parcerias entre as crianças. O critério utilizado para a seleção do material para a análise foi escolher as sessões em que participou o mesmo grupo de crianças, ou na sua maioria. A partir dessas sessões foram definidos oito episódios para análise os quais compõem o corpus da pesquisa. Para o exame das interações no grupo, foram definidas cinco categorias para a análise de cada episódio: a) a formação das parcerias; b) os brinquedos como mediadores; c) o espaço físico como canalizador das interações; d) a cultura de grupo e, e) as brincadeiras como contexto da permanência e da novidade.

Para a análise da organização da brincadeira das crianças e que apresenta dados referentes a cultura do grupo infantil selecionamos o episódio "Em torno da árvore de Natal". Este episódio faz parte de uma das sessões de filmagem realizadas no mês de dezembro, quando o grupo de crianças já estava mais familiarizado. Participaram dessa sessão seis crianças: Tabata, Lucas, Igor, Taíse, Leo e India, cujas idades e turma de origem estão na tabela abaixo. 
TABELA 1 Identificação das Crianças por Idade e suas Respectivas Turmas

\begin{tabular}{lcc}
\hline Nome da criança & Idade da criança & $\begin{array}{c}\text { Turma na qual estava } \\
\text { matriculada }\end{array}$ \\
\hline 1. Tabata & 32 meses & Maternal I \\
2. Lucas & 35 meses & Maternal I \\
3. Igor & 49 meses & Maternal II \\
4. Taíse & 47 meses & Maternal II \\
5. Leo & 50 meses & Jardim I \\
6. India & 54 meses & Jardim I \\
\hline
\end{tabular}

\section{RESULTADOS E DISCUSSÃO}

A seguir é possível visualizar a descrição do episódio interativo com a duração de um minuto e meio, no qual é possível identificar as cinco categorias de análise definidas para a compreensão dos processos de significação destas crianças: a) a formação das parcerias; b) os brinquedos como mediadores; c) o espaço físico como canalizador das interações; d) a cultura de grupo e, e) as brincadeiras como contexto da permanência e da novidade. Os brinquedos utilizados pelas crianças neste episódio foram: fantoches, carrinhos, carrinhos de bonecas, loucinhas, binóculo, estetoscópio, jogo de encaixe (Lig-Lig), vassourinha, serrote, martelo, alicate de plástico, óculos e cones de plástico.

Transcrição do episódio "Em torno da árvore de Natal":

(5:00) India vira-se e fala para Tabata, que está mais afastada, próxima ao monte dos brinquedos: "eu moro contigo, né?..né?" apontando-lhe o dedo. Taíse aproxima-se também da árvore de Natal e olhando para India fala: "até comigo, né? Né, coisa?", num tom de voz suave. Lucas pára de bater o martelo e olha para as meninas. India concorda: "hum hum!" e volta a tocar no pinheirinho. Igor, sentado no chão de frente e próximo da árvore, fala alto: "não mora não. Tu mora é lá no morro!" Tabata olha para India que diz: "contigo não. Eu moro com ele e com ele", apontando para Igor e Tabata. "Eu moro com o teu irmão, né?", diz India olhando para Tabata, observadas por Igor que faz movimento afirmativo com a cabeça. Lucas aproxima-se do grupo, agacha-se e olha para os brinquedos do monte enquanto Tabata observa as crianças que estão em volta da árvore. Taíse, balançando seu corpo, fala para Igor com uma expressão séria: "eu moro no morro!" India responde para Taíse: "eu moro mais no morro, mais no céu do que tu!" Taíse responde olhando para India, que voltou a tocar na árvore: "eu não moro lá no céu!" Lucas, de longe, grita: "Não mexe!" para India, que se vira para ele, cruza os braços, recosta-se na parede com expressão de zangada e, colocando as mãos na cintura, lhe pergunta: "aqui é a tua sala?". Lucas responde à India em voz alta: "é!", observado por Taíse. Tabata aproxima-se de India com uma expressão séria e fala: "é minha sala..." India fala: "aqui eu só vendo, né Tabata? Eu tô só vendo”. Taíse e Leo olham para a árvore de natal. Lucas, sentado no chão junto de Tabata, brinca com um martelo e um serrote. Tabata de pé, olha para India que mexe na árvore de Natal nomeando as cores das bolinhas enquanto as toca com o dedo indicador direito: "aqui: amarelo, vermelho, vermelho... amarelo, vermelho, vermelho". Leo e Taíse, em pé lado a lado, observam as bolinhas tocadas por India. Igor, sentado no chão, brinca com o binóculo, de cabeça bai$\mathrm{xa}$, olha algumas vezes para ver o que as outras crianças estão fazendo e volta a se entreter com o binóculo. Taíse olha India apontar para a árvore. Leo toca com o serrote uma das bolinhas que India não havia nomeado e fala: "vermelho." Taíse fica na ponta dos pés e, tocando uma bolinha, diz: "azul." India toca outra bolinha e fala: "azul...". Taíse toca outra também. India aproxima-se de Taíse e a empurra enquanto estica a mão direita para tocar em uma bolinha que está um pouco mais no alto da árvore e fala: "azul!". Taíse observa India mostrar as bolinhas, dá um pulo para frente e toca mais uma vez uma das bolinhas. Tabata aproxima-se do grupo, mostra uma colherinha cantarolando e olhando para Taíse: "ó, peguei, peguei a minha faca!" E olha para a filmadora enquanto Taíse, Leo e India estão voltados para a árvore de Natal. India dá um pulo para tentar alcançar outra bolinha, fica um pouco ofegante e dá um passo para trás. Leo olha para Lucas que se aproxima falando: "Aqui oh! Aqui oh!", apontando com o martelo em direção a uma das bolinhas da árvore. Taíse dá vários saltos tentando tocar a bolinha indicada por Lucas. India, posicionada atrás de Taíse, bate palmas enquanto fala: "capaz que vocês vão consegui! eu quero ver quem é baixinha? Olha para Taíse e fala: Quem é baixinha? India dá uns saltos tentando tocar a bolinha azul do alto da árvore, fica ofegante e olha para Taíse sorrindo. Leo, 
Tabata, Taíse, Lucas e Igor observam India saltar mais três vezes, tocar na bolinha e bater palmas enquanto fala para as crianças que estão a sua volta: "só pra vocês não consegui". Dirigindo-se para Tabata diz: "agora a Tabata pega" India pega no colo Tabata, que estica a mão direita para tocar a bolinha, enquanto segura a colher na mão esquerda. Taíse salta no mesmo lugar e diz: “eu também consigo". Enquanto Igor manuseia o binóculo, Leo, Taíse e Lucas observam Tabata, no colo de India, tocar na bolinha. India diz para Tabata: "na estrelinha do outro lado!”, geme, balança, coloca Tabata no chão e, olhando para a árvore, fala: "agora aqui, ó Tabata!" Taíse vai até o lugar onde estavam India e Tabata e dá três pulos para tocar na bolinha azul. Lucas, atrás de Taíse, bate com o martelo num prego da parede e olha algumas vezes as colegas tocarem na árvore. India ergue Tabata, que toca em algumas bolinhas, e lhe diz: “não, Tabata! aí não! Ali.” Tabata começa a perder o equilíbrio no colo de India, que balança e geme ao segurar a menina, observadas por Leo, Taíse e Lucas. India coloca Tabata no chão e, tocando na bolinha vermelha, lhe diz: “aqui, ó nega, aquiii.". Tabata, olhando para a bolinha, fala: "Tá! ’enquanto movimenta a cabeça afirmativamente. India volta a pegar Tabata no colo, mas desta vez a pequena fica mal posicionada e reclama com expressão de medo: “aí, aí, aí!'”India coloca Tabata no chão. Taíse se coloca na frente de India e diz: "eu consigo" e bate palmas eufórica. India ofegante diz: "vem!" e pega Taíse no colo enquanto esta fala: "pega eu aqui!". Leo continua olhando para as meninas que tentam tocar nas bolinhas da árvore de natal (6:30)

Os resultados serão discutidos a seguir de acordo com as cinco categorias de análise. No início do episódio, no que se refere à formação das parcerias (categoria a) o interesse por um mesmo elemento por diferentes crianças atuou para a formação destas (árvore de natal). As parcerias mais estáveis se formaram entre as meninas India, Tabata e Taíse utilizando a árvore como mediador para as interações. Os meninos participaram da atividade mais na posição de observadores do que de participantes da brincadeira. Lucas é exceção: o menino está atento ao que faz India, e sinaliza constantemente para a menina que não deve tocar na árvore de natal.

Também foram observadas parcerias de crianças (categoria a) que se organizaram ao redor de um tema comum. As crianças trouxeram o fato de morarem próximas como recurso para o estabelecimento de uma conversa compartilhada entre elas. Nesta, participou quem se identificou com o local de moradia ou grau de parentesco, como India e Tabata que são primas e vizinhas. Igor, mesmo distante e manuseando um binóculo de cabeça baixa, participa da interação complementando a fala de India. Taíse também se permite participar ativamente da conversa, pois é vizinha das meninas. O que se pode perceber é que India não se referia ao fato de morar no morro, mas à sua relação de parentesco com Tabata. A partir da fala de Igor que traz o local de moradia como novo elemento, Taíse explicita a sua também condição de moradora do morro. Esta conversa rápida possibilita a participação da maioria das crianças do grupo que se identificam por morarem no morro e estabelecem isto como critério para a interação, formando um grupo por partilharem do mesmo local de moradia.

Por meio da categoria os brinquedos como mediadores (categoria b), o caráter simbólico de um elemento do ambiente - a árvore de Natal - contribuiu para que todos os participantes se envolvam na mesma atividade ao redor dele. India e Taíse buscam tocar nas bolinhas que estão nos ramos da árvore de Natal, observadas por Leo e Igor, enquanto Lucas e Tabata a tocam também. O sentido produzido por India sobre a árvore de natal é aos poucos compartilhado por outras crianças que, ao imitarem suas ações, participam do enredo que circunscreve suas interações.

No que tange a categoria o espaço físico como canalizador das interações (categoria c), a sala de atividades possibilitou uma série de ações e limitou outras na brincadeira. No arranjo espacial dessa sala não há delimitação de áreas para atividades específicas, expressando a perspectiva dos adultos da instituição sobre como o ambiente deve estar organizado para a promoção do desenvolvimento das pessoas que nele se encontram. O significado da sala na instituição é trazido por algumas crianças e usado com argumento para algumas ações: India demonstra o estranhamento a esta sala de atividades, visto que a sua é outra a qual Leo também utiliza, pois possuem a mesma idade e fazem parte da mesma turma. Ela procura confirmar com as crianças do grupo a quem pertence aquele espaço. Parece que as crianças não conhecem as salas de atividades das outras turmas e compartilham apenas os espaços comuns como o refeitório, o parque e os banheiros.

A zona circunscrita para a atividade infantil mais evidente é o monte de brinquedos no centro da sala definido pela pesquisadora e em torno dele as crianças se distribuem. A inserção da árvore de Natal como um novo elemento deste meio (colocado pela educadora), possibilitou que as ações destas crianças fossem ressignificadas na atividade desenvolvida em torno deste elemento. As ações de tocar na árvore desencadeiam uma disputa entre India e Lucas que são 
crianças que pertencem a turmas distintas. Esta sala é de Tabata e Lucas que sinaliza que não é para mexer na árvore, reproduzindo o discurso de alguém para manter o artefato como "enfeite" e não como brinquedo.

$\mathrm{Na}$ categoria a cultura de grupo (categoria d) as negociações e disputas em torno da árvore demonstram iniciativas de impor-se ao outro. India e Lucas alternam-se nessa disputa. A expressão séria do rosto e os braços cruzados de India representam o sentido que ela atribuiu à repreensão feita por Lucas que interrompeu seu prazer de brincar com a árvore. Tabata e Taíse formam parcerias com India, mas não a enfrentam. Tabata é convidada por India para brincar, enquanto que Taíse se posiciona oferecendo-se para participar da atividade iniciada pela menina. Nestas negociações e disputas, as crianças manifestam modos de interagir e estratégias definidas por elas próprias para os desafios e parcerias das interações do grupo. A atividade de mexer na árvore é feita com novas regras, diferentes das colocadas pela instituição e as crianças consideram que a regra adequada é poder mexer na árvore, pois isso lhes dá prazer. A alegria das meninas em tocar na árvore é manifestada por ações como bater palmas, balançar o corpo de um lado para o outro e sorrir.

Regras anteriormente construídas são modificadas pela ação das crianças. Ou seja, na exploração de um objeto, são criadas normas, regras, significações. No episódio, ações e emoções observadas indicam, inicialmente, um enfrentamento destas crianças para, no decorrer do episódio, apontar um possível consenso acerca do significado atribuído à árvore: inicialmente ela não deve ser tocada, regra que é ao longo das interações modificada quando a árvore é tocada também por Taíse e Tabata que compartilham o significado atribuído por India à árvore de natal.

É por meio do brincar que a criança tem a possibilidade de reviver situações conflitantes que lhe causam excitação, raiva, ansiedade, ou ainda, situações agradáveis como alegria. Assim, pelo brincar experienciam e trabalham emoções às vezes difíceis de suportar (Dornelles, 2001). Deste modo, as crianças interpretam a realidade segundo uma lógica própria da infância, distinta da lógica adulta, na qual a imitação, a observação das ações dos outros, a negociação verbal de papéis e regras são recursos usados pelas crianças para estruturar a ação coletiva e construir novos significados trazendo novos elementos, abandonando outros, interrompendo e/ou alterando o enredo. Nesse processo, o tempo e o espaço são utilizados pelas crianças de maneira criativa, na brincadeira.
Com a categoria as brincadeiras como contexto da permanência e da novidade (categoria e) novos sentidos são construídos no grupo. No episódio, as ações relacionadas à árvore de Natal retomam significados construídos pelas crianças do grupo. India e Lucas produzem seus sentidos no confronto de significados que a árvore de Natal tem para cada uma das crianças, construído na experiência em sua cultura e nas atividades que desenvolvem no espaço da creche, na situação de brincadeira.

Algumas atitudes de liderança por parte de algumas crianças continuaram, mas novas posições em relação aos companheiros puderam ser notadas. Neste episódio, India obedece, mesmo que temporariamente, à ordem dada por Lucas. Aqui se observa uma criança mais velha se submeter, mesmo temporariamente, a uma criança mais nova, indicando que as interações mudam o fluxo do que convencionalmente se pensa sobre a submissão de crianças mais novas às mais velhas. Lucas não determina a formação das parcerias, mas enfrenta India que disputa com as demais a posse pelos brinquedos e busca definir o enredo das brincadeiras.

O episódio analisado possibilita apontar que a construção de significados/sentidos é um ato que ocorre na relação com o outro em um processo dinâmico mediado, no caso, por gestos e palavras associados a um objeto focal. Vários elementos vão configurando a situação do grupo: as meninas menores (Taíse e Tabata) têm dificuldade em alcançar as bolinhas da árvore e isto as faz solicitar a ajuda da maior (India) que se dispõe a auxiliá-las suspendendo-as para que toquem nas bolinhas. Pode-se perceber que somente as meninas entraram na brincadeira de alcançar as bolinhas da árvore de natal enquanto que os meninos as observavam. Nessa estrutura de grupo, as crianças partem das regras da cultura adulta, que diz que não se pode tocar nas bolas da árvore de Natal, mas descobrem que, a partir de uma organização criada por elas mesmas, podem tocar na árvore sem estragá-la. Por meio da ludicidade, as crianças recriam significados conforme elas assumem determinadas ações nas situações criadas pelo grupo.

As negociações e disputas em torno da árvore, demonstram também iniciativas de participar do jogo. India convida Tabata para brincar enquanto que Taíse se posiciona oferecendo-se para participar da atividade iniciada pela menina. Elas o fazem se pondo na posição de serem pegas no colo e suspensas. Por meio de negociações, as crianças manifestam modos de interagir e estratégias definidas por elas próprias para os desafios e parcerias das interações do grupo. 
$\mathrm{Na}$ análise do episódio podemos utilizar o conceito de reprodução interpretativa proposto por Corsaro (2005), conforme as crianças atribuem sentidos à organização espacial (a colocação da árvore de Natal na sala de atividades) e temporal (proximidade com a festividade do Natal), à sequência das atividades na brincadeira, às regras impostas pela instituição às crianças e por elas evocadas e negociadas no grupo, ao uso do material e dos brinquedos disponíveis na instituição para a brincadeira, aspectos que salientam uma rotina estabelecida pelos adultos para orientar as práticas na instituição. Nas atividades observadas, as crianças desempenharam determinados papéis e ocuparam determinadas posições, delimitando as interações que estabeleceram nas situações vividas. $\mathrm{Na}$ brincadeira, as interações envolveram de início, crianças de mesma idade, mas no desenrolar das ações, foram sendo observadas parcerias entre meninas oriundas de turmas distintas, em especial quando o alcançar as bolas requereu ajuda de alguém mais velho e com maior força física para erguer a criança menor.

O faz-de-conta e a imitação foram os recursos utilizados pelas meninas para atuarem no plano coletivo e individual, possibilitando-lhes a construção de um sentido de si. Nas diversas situações criadas na brincadeira se pode tomar a noção de individuação como complementar nesse processo. As crianças do grupo necessitaram reconhecer suas ações e as dos outros nas situações interativas para negociarem os significados referentes às atividades partilhadas.

\section{CONCLUSÕES}

As reflexões sobre a forma como as crianças se organizam em suas brincadeiras fornecem indicativos para se pensar como estas compreendem o mundo a sua volta e como são capazes de recriá-lo. É no campo interacional da brincadeira que a construção de significados sobre as ações se estabelece e se desfaz com diferentes crianças, constituindo o que a literatura denomina de cultura do grupo de brinquedo (Carvalho $\&$ Pedrosa, 2002). No grupo de brincadeira, a criança se depara com várias práticas sociais culturalmente significadas. Nele, a imitação, a observação das ações dos outros, a negociação verbal de papéis e regras são recursos usados pelas crianças para estruturar a ação coletiva e construir novos significados. $\mathrm{Na}$ brincadeira, muitas ações acontecem ao mesmo tempo, trazendo novos elementos, abandonando outros, interrompendo e/ou alterando o enredo, ou ainda regras e normas assumidas no brincar propiciam espaço para que a criança se comporte de maneira mais avançada do que a sua idade permitiria (Dornelles, 2001).
Nesse processo, o tempo e o espaço são utilizados pelas crianças de maneira criativa, possibilitando-lhes partilhar novos significados no aqui-e-agora da situação interativa à medida que respondem às ações e falas do outro e questionam, fortalecem ou reconstroem o valor que determinado objeto ou situação possui para elas. Isso exige dos envolvidos a possibilidade de transformar os significados historicamente construídos em linhas de fuga que surgem nos confrontos, nas situações de frustração ou desprazer presentes na brincadeira. Esta, não somente se constituiu em um espaço para a intersubjetividade, mas também exigiu das crianças uma postura ativa para lidar com os conflitos e desafios constituintes das relações com o outro (Vygotsky, 2007).

No aqui-e-agora da situação da interação, o tempo e a experiência de cada criança são fundamentais para a negociação das significações. Contudo, as ações e significados estão intrinsecamente relacionados ao contexto da creche, às pessoas e suas histórias de vida, às dimensões temporais e aos campos interativos que compõem os elementos da complexa rede de fatores promotores do desenvolvimento humano (RossettiFerreira \& cols., 2004). A instituição de Educação Infantil, como um contexto carregado de significações, proporciona à criança atividades às quais ela tem que atribuir significados pela repetição ou pela criação da novidade, e nas quais ela se reconhece individual e coletivamente. Deste modo, a partir do momento que a criança cresce e passa a dividir espaços coletivos com as demais, têm a possibilidade de aprender conjuntamente, partilhando brinquedos, dividindo tarefas e de fato conseguindo viver de maneira mais socializadora nos espaços os quais circula (Dornelles, 2001). As instituições de Educação Infantil, enquanto meio cultural e social e, portanto político, delimitam o campo de interação dos adultos e crianças e das crianças entre si. As atividades organizadas nesse contexto, assim como as que ocorrem no ambiente familiar, são oportunidades para o confronto de ações e também de significações, que podem ser confirmadas, transformadas ou extintas pelas pessoas. Estudos observacionais podem fornecer elementos que apontem a forma como as crianças elaboram elementos culturais e os re-significam de modo próprio em uma cultura de grupo, abrindo espaço para novas formas de Educação da Infância.

O estudo com crianças constitui-se em um desafio pelo trabalho de buscar compreender as dinâmicas que se estabelecem nas interações que elas criam segundo suas próprias determinações e sem a interferência direta do adulto, embora indiretamente haja a escolha 
dos brinquedos, o arranjo dos espaços etc. A análise das interações das crianças em situação de brincadeira oferece oportunidade para alguns questionamentos: estamos realmente atentos ao que as crianças têm a nos ensinar por meio da cultura que constroem nos espaços educativos? Será que as estamos considerando seres realmente ativos no seu processo de constituição e participantes da construção da nossa sociedade? Estamos aprendendo que as crianças são capazes de fugir das determinações impostas pela idade, sexo e classe social quando criam culturas com seus pares? Sem dúvida, elas ainda têm muito que nos ensinar no que se refere a cultura que se cria no grupo de brincadeiras.

\section{REFERÊNCIAS}

Anjos, A. M., Amorim, K. S., Franchi, E., Vasconcelos, C. R., \& Rossetti-Ferreira, M. C. (2004). Interações de bebês em creche. Estudos de Psicologia (Natal), 9(3), 513-522.

Bahkthin, M. (1992). Estética da criação verbal (M. E. G. G. Pereira, Trad.). São Paulo: Martins Fontes.

Corsaro, W. (2005). The sociology of childhood. Thousand Oaks, CA: Pine Forge Press.

Carvalho, A. M. A., \& Pedrosa, M. I. (2002). Cultura no grupo de brinquedo. Estudos de Psicologia (Natal), 7(1), 181-188.

Delgado, A. C. C., \& Müller, F. (2005a). Em busca de metodologias investigativas com as crianças e suas culturas. Cadernos de Pesquisa, 35, 161-179.

Delgado, A. C. C., \& Müller, F. (2005b). Sociologia da infância: Pesquisa com crianças. Educação e Sociedade, 26, 351-360.

Delvan, J. S. (2007). Um estudo sobre os processos interativos de crianças de 2 a 4 anos em situação de brincadeira a partir da noção de rede de significações - RedSig. Tese de doutorado não-publicada, Faculdade de Filosofia Ciências e Letras de Ribeirão Preto.

Dornelles, L. V. (2001). Na escola infantil todo mundo brinca se você brinca. Em C. M. Craidy \& G. E P. S. Kraecher (Orgs.), Educação infantil: Pra que te quero? (pp. 101-121). Porto Alegre: Artmed.

Ferreira, M. (1999). "Crescer e aparecer" ou... para uma sociologia da infância. Educação, Sociedade e Culturas, 3, 3-12.

Ferreira, M. (2002a). Os estranhos "sabores" da perplexidade numa etnografia com crianças em jardim de infância. Em T. H.
Caria (Org.), Experiência etnográfica em ciências sociais (pp.149-166). Porto: Afrontamento.

Ferreira, M. (2002b). O trabalho de fronteira nas relações entre gêneros em espaços de "brincar de faz de conta". Exaequo, 7, 113-128.

Franchi E., Vasconcelos, C. R., \& Ferreira, M. C. R. (2002). Crianças pequenas brincando em creche: A possibilidade de múltiplos pontos de vista. Estudos de Psicologia (Natal), 7, 259-270.

Javeu, C. (2005). Criança, infância(s), crianças: Que objetivo dar a uma ciência social da infância? Educação e Sociedade, 26, 379-389.

Montandon, C. (2001). Sociologia da infância: Balanço dos trabalhos de língua inglesa. Cadernos de Pesquisa, 112, 33-60.

Mollo-Bouvier, S. (2005). Transformação dos modos de socialização das crianças: Uma abordagem sociológica. Educação $e$ Sociedade, 91, 391-403.

Newman, F., \& Holzman, L. (2002). Lev Vygotsky: Cientista revolucionário. São Paulo: Loyola.

Oliveira, Z. M. R. (1988). Jogos de papéis: Uma perspectiva para análise do desenvolvimento humano. Tese de doutorado não-publicada, Universidade de São Paulo.

Oliveira, Z. M. R. (1995). Interações sociais e desenvolvimento: A perspectiva sócio-histórica. Cadernos CEDES, 15, 50-63.

Pedrosa, M. I., \& Carvalho, A. M. A. (2005). Análise qualitativa de episódios de interação: Uma reflexão sobre procedimentos e formas de uso. Psicologia: Reflexão e Crítica, 18, 431-442.

Rossetti-Ferreira, M. C., Amorim, K., \& Silva, A. P. S. (2004). Rede de significações: Alguns conceitos básicos. Em M. C. Rossetti-Ferreira, K. S. Amorim, A. P. S. Silva, A. M. A. Carvalho (Orgs.), Rede de significações e o estudo do desenvolvimento humano (pp. 23-33). Porto Alegre: Artes Médicas.

Sarmento, M. J. (2005). Gerações e alteridade: Interrogações a partir da sociologia da infância. Educação e Sociedade, 26, 361-378.

Sirota, R. (2001). Emergência de uma sociologia da infância: Evolução do objeto e do olhar. Cadernos de Pesquisa, 112, 7-31.

Vygotsky, L. S. (2007). A formação social da mente (J. C. Neto, L. S. M. Barreto e S. C. Afeche, Trads.). São Paulo: Martins Fontes.

Recebido: 16/12/2008

Última revisão: $12 / 04 / 2010$ Aceite final: 20/04/2010

\section{Sobre as autoras:}

Josiane da Silva Delvan: Doutora. Professora de Psicologia do Desenvolvimento Humano do curso de Psicologia da Universidade do Vale do Itajaí (UNIVALI).

Maiara Pereira Cunha: Acadêmica do curso de Psicologia da Universidade do Vale do Itajaí.

Endereço para correspondência: Universidade do Vale do Itajaí - Curso de Psicologia - Rua Uruguai, 458 - Bloco 25 b, sala 401 Centro - 88302-202 Itajaí - SC. Endereço eletrônico: josidelvan@univali.br; maiara_pereira@yahoo.com.br. 